\section{Leadership in Social Organizations from Primates to Humans: The Role of a Leader in Changing Team Direction}

\section{Aryeh Gotsdanker*}

Department of Psychology, Walden University, Israel

\begin{abstract}
This study will propose a new theory of leadership phenomenon by comparing natural mechanisms in human society with those existing in the animal world. Animals' social systems have similar structure, dominance, influence, manipulations (Machiavelli's), yet have no stereotypes and are not as complex as human society. Observation of animal social systems and extrapolation on human society leads to a fresh perspective on the phenomenon of leadership: the role-based theory of leadership. This theory can guide subsequent studies, which may test such conclusions as the advantage of natural competitive selection of leaders over artificial breeding in real organizations. The role-based leadership theory proposes to shift the focus of attention of researchers from trying to understand who became a leader and why, to understanding leadership as a continued struggle of rivals.
\end{abstract}

Keywords: Leadership; Role-based leadership; Theoretical research; Animal psychology; Organizational psychology; Management; Influence

\section{Introduction}

An ongoing interest in leadership throughout the recent 50-plus years attests to the importance of this subject, which is likely connected to the hope and intention to improve group efficacy by selecting and assigning the right leader. But, the prevalence of the topic is driven by a core human motive - need for power [1-3]. An interest in the subject of leadership is caused by desire to gain knowledge and skills which will help us to assume power. The purpose of leadership research is to find the core of the leadership phenomenon. What is intrinsic leadership power, who should take on this leader role and how? This research focuses on leadership as a social function, instead of related aspects, such as: how to obtain leadership (power), who is that "Great man" to be assigned as a leader, and what traits characterize the best leader (dominant). Findings of this research could add to the knowledge base and change the perception of leadership from a result (who deserves the role) to a process (how the role is deserved).

\section{Leadership Theories}

After much investigation and research performed on the topic we still have no common definition of what leadership is. From the scientific point of view, leadership has no stable paradigm; it is not a scientific term with a formal, standardized definition [4]. Every author who wrote on the topic evaluated one or a few facets of the leadership. Contingency theory confirms that there is no optimal way to lead a company; it is strongly dependent on internal and external factors. A contingent leader should apply his or her own style to the right situation [5-7]. Situational leadership theory and Path-goal theory educate managers on how to adapt their leadership style to influence subordinates better [8-11].

Transactional leadership theory focuses more on routines and procedures to reach maturity and enhance the performance of organizations by improving organizational structures and rules [12]. Transformational leadership theory concerns the reciprocal efforts of leaders and subordinates to increase organizational efficacy by improving morality and motivation [12,13]. A great deal of research has been performed in search of the right personality, aiming to identify necessary traits of an effective leader [14-17], but results are case-, sample-, and culture-dependent and could not be generalized across the whole leadership topic $[18,19]$. Even a self-leadership topic has been investigated [20].

Charismatic leadership theory is the only one that distinguishes itself from others. Theorists agree that a Charismatic leader has an exceptional influence on the followers and his authority depends on his perceived legitimacy [21], or, as Weber [22] defined: "resting on devotion to the exceptional sanctity, heroism or exemplary character of an individual person, and of the normative patterns or order revealed or ordained by him".

From this variety of leadership researches, only two common characteristics emerge: 1) a leader has followers, and 2) a leader could influence his followers [4].

Having defined what is meant by leadership (followers and influence), it follows that leadership is an organizational role. One of the thorough writers on organizations has been Richard Scott, whose work we will draw on heavily from time to time. Scott defined organizations as such: "Organizations are conceived as social structures created by individuals to support the collaborative pursuit of specified goals" [7]. So, the main aim of a leader is to persuade his followers to move in the direction of achieving organizational goals. Thus, the leadership phenomenon should be defined as an organizational role which leads the collaborative pursuit of specified goals. The importance of the role of and possibility to have plural leaders in an organization will be discussed later in this paper.

This complexity of the leadership phenomenon comes from involvement of interrelated aspects such as: personal motives, employee motivation, influence and persuasiveness, stereotypes, and need for power $[2,3]$. In order to develop a generalized theory of leadership,

*Corresponding author: Aryeh Gotsdanker, Department of Psychology, Walden University, Israel, Tel: +972546598989; E-mail: gotsdanker@gmail.com

Received: June 01, 2018; Accepted: June 20, 2018; Published: June 27, 2018

Citation: Gotsdanker A (2018) Leadership in Social Organizations from Primates to Humans: The Role of a Leader in Changing Team Direction. Clin Exp Psychol 3 : 195. doi: $10.4172 / 2471-2701.1000195$

Copyright: (c) 2018 Gotsdanker A. This is an open-access article distributed under the terms of the Creative Commons Attribution License, which permits unrestricted use, distribution, and reproduction in any medium, provided the original author and source are credited. 
it has been looking for a society which is minimally affected by stereotypes, has no pay-work relations or formal organizations. By eliminating these factors to the greatest extent possible, it is aimed to reduce subjective attitudes, of both leaders and followers towards each other, and the impact of culture-wide opinions and stereotypes. It has been found these pure societies free of stereotypes and complexity in animal behavior, in the sciences of ethology and ecology. Learning what is known about leadership in the animal world helped to develop generalized the role-based leadership theory, which is applicable for human leadership on an abstract level, and which provides the basis for a comprehensive understanding of the leadership phenomenon.

Numerous ethology studies have attempted to explain animals' dominance and rank phenomena, and they have found that animal societies could have politics $[23,24]$, that animals could exploit and manipulate each other $[23,25,26]$, and that animals have ranks and hierarchical structures [27,28]. According to Darwin's theory of evolution [29], this kind of collective behavior with roles is a result of Natural Selection, and the competition for food and ability to breed. Understanding of animal behavior could serve as the basis for the extrapolation and development of a generalized theory of human leadership.

\section{Animal Social Behavior}

In animal society, sustainable behavioral strategies can be observed. Following a particular strategy (role), the individual can behave in its community as a meek conformist ("dove") or as an irreconcilable aggressor ("hawk") [30]. Because the population exists in the multidimensional space, favorable access to resources - including "internal" or reproductive resources - can be gained by representatives of different strategies at the same time [31]. The balance between alternative strategies can be very tense. While one individual might adopt a clearly-defined role and act it out throughout its whole life while another may always transition between different roles depending on the situation, acting, for example, as a "hawk" on his or her own territory, while adopting the role of the "dove" in a situation with a stranger [32].

Maynard and Smith [33], applying the mathematical game theory to the description of the animal behavioral stereotypes [34], developed the theory of evolutionarily stable strategies, explaining that stable conditions maintain a constant numerical value of population carriers of alternative strategies, supporting some level of competition. According to John Maynard Smith, evolutionarily stable strategy is a set of sustainable patterns of behavior that are used by individuals in social competition in conditions where resources are limited. The main characteristic of the evolutionary stable strategy is the selectivity of behavioral strategies demonstrated towards others, forming during the natural selection.

\section{The Dominance between Animals}

In the early 20s, the Norwegian environmentalist, exploring the structure of relationships in groups of hens and ducks, discovered a strict order of dominant ranks. Each individual either dominates its partner or subordinates to it. These relationships were named the famous "peck-order". During the sorting out of hierarchy between the birds, gradually the one that dominates all others. Below it stands a bird of the second rank, which dominates over all, except the main one, and so on, down to the very bottom of the hierarchy, where the bird that is under all other group members stands. The hierarchy is formed by the conflict of birds in the struggle for limited resources (a place on a roost, food), and on the early stages of this establishment there are frequent fights. Once the hierarchy is established, it becomes equally one of dominance and subordination. Usually, when the more dominant bird approaches, the subordinate individuals yield to it without resistance [27].

On further investigation of hierarchy and domination in animal life, biologists began to consider that the dominant animal that eats more or longer controls access to the feeding-trough. More generally, dominance is the ability to access resources ignoring the interests of others. It turned out that when comparing different measures of dominance (for food, water, territory, access to a sexual partner, the opportunity to go to the nest, and so forth) the correlation between these indicators may be weak or totally absent. In other words, a single syndrome of dominance wasn't found; it was not possible to detect some absolute "the Great Man" [35]. It turns out that domination is the motive that makes animals compete for social status, which will provide the preferential access to the required resources.

\section{Manipulation between Animals}

For the description of the phenomenon of «political» struggle between animals, De Waal has proposed the term "Machiavellian intelligence" in his book [23]. Chimpanzee politics in the narrow sense of the term is understood as the ability to manipulate the behavior of the other, to use them as "living tools." In his experiments, De Waal has repeatedly observed examples of monkeys using the labor of others to achieve their goals. For example, in one experiment, in order to get a box of food, the monkeys had to pull two ropes jointly and simultaneously. The monkeys soon learned and mastered the necessary cooperation to obtain their food. Interestingly, when one monkey was hungry, while the other was fed up and did not want to pull the rope, the hungry monkey forced its partner to work, giving it a pair of cuffs.

A very interesting experiment was conducted on rats [26]. Researchers took six rats and put them in a cage, but the food was moved to another room, which was united with the current cell through an obstacle course, which here consisted of one-meter-long baths. Rats were required to pass one meter of water in order to reach the feed. Irrespective of the specific individuals composing the group, the social organization was rebuilt in the same way. Two rats took the role of exploiters; they sat in their cage and forced other rats to swim for food. Two rats were swimmers and moved food from the manger to the cage, at which point it was seized by the exploiters. One rat was depressed and was satisfied with the crumbs, and one was independent, sailing for food and sharing with no one. A most notable finding is that when the researchers collected six rats that in other conditions fulfilled the role of the exploiters and placed them in one cage, after some fight, the roles were distributed as in the original experiment. In fact, the same role distribution happened with any other rats which had previously assumed the same role.

A low rank individual can achieve the desired goal with clever workarounds. So, if the one wants to reach the highest rank of the hierarchy, it must be able to plan its actions and to manipulate the actions of subordinated individuals, many of which may be stronger than it is.

\section{Leadership between Animals}

In the community of pigtail-monkeys, the social role of a dominating individual is very concise, clear and sufficiently stable [28]. An individual occupying a leading role can punish and encourage, expel from the group, select meals, and choose females. But, most importantly, the dominant male determines where the group will get food, in which territory. In case of disputes and conflicts with other 
individuals or groups, the dominant male, by its personal example of strength and courage, begins the struggle and directs its supporters to follow suit, or retreats and takes its group along. This example is clearly shown in the movie Monkey Thieves broadcasted on the National Geographic channel [36].

At the same time, this leadership may be very situational, as in the "role hierarchy" in packs of stray dogs, as described by Poyarkov [37]. In such communities there are some "experts," as demonstrated by several examples. When meeting with a foreign troop, the powerful dog goes ahead; the schedule of visiting the garbage can, depending on when and what is brought there, "makes" a dog that has a good memory and intelligence; when meeting with a stranger, some funny puppy is on the front line, but if the person is met in twilight and has something that dogs can steal, another member of the troop becomes a leader. Accordingly, the flock obeys different leaders in different situations. Similar relationships can be seen in the analysis of interaction in communities of other animals.

Thus, we can note that the distribution of roles is peculiar not only to human organizations, but to many species of animals, for whom it is nothing other than a result of evolution and struggle for survival and procreation. This role can be functional (profession) and hierarchical (dominance, obedience), and these roles can be as stable «for the whole life», and situational. The internal motive of domination, like human «need for power» $[2,3]$, is that driver that starts this social mechanism of competition, the result of which we can see as a permanent ability to adapt to the changing world, and ultimately, evolution. If for the animal world, the competition for social roles is nothing more than one of the elements of evolution, then an analogy to human social organization may lead to the following conclusion: leadership is the process of competition for social roles, driven by motives of power and recognition, and results in the capacity to adapt to changing environmental conditions.

\section{Conceptualization of Role-Based Leadership Theory}

Dominance in its basic meaning, which came to us from ethology, is just a competition for priority access to resources. Neither in animal nor human social structures is there a point in searching for the ideal traits of a leader, the best leadership qualities, etc., as this process is very dynamic and highly dependent on the current circumstances. The very meaning of this struggle is that the individual most adapted to the changing environmental conditions has priority access to resources.

Leadership is a desirable social role, for the assumption of which social competition occurs. In connection with the idea that the phenomenon of leadership is essentially a process, not the result, it becomes clear why such a long study of this phenomenon has not resulted in any comprehensive picture. Already many theories of leadership exist, separate magazines published, various trainings conducted; there is still no common understanding or established paradigm.

In the animal kingdom, the role of dominant individual is a result of competition. A current leader might be not as strong as its young competitor but still able to hold the role. From the evolutionary point of view, the personal characteristics of an individual who holds the role of leader make no sense. The replacement of a leader is not an instant process; it is not a mere question about the power of two or more individuals, but rather the dynamic process as related to social connections and relationship in the group. Usually replacement happens when a group is in a crisis (lack of food, attacked by other groups), or when a leader is old and ineffectual, among other reasons.
Lessons from nature show us that the role of leader could be situational, as in the example with dogs [37], or not visible at all. Animals follow a leader in order to meet basic needs: to get food or to breed. When it is complicated to satisfy these needs alone, evolution teaches them to survive in social communities. The basic motive of need for power drives this distribution of individuals among different social roles. The similarity of domination and leadership in animal social systems and human societies provides relevant insight on the phenomenon. Extrapolating this knowledge of animal behavior to organizational settings gives better understanding of core, natural leadership. Humans, according to Maslow, have an extended pyramid of desires [38]. These extended needs differentiate human leadership from that of animals, and provide extra complexity to the topic.

In summary, proposed the following hypotheses derived from the theory:

a)Humans follow leaders when it is not possible or more complex to satisfy a particular need alone, and there may be different leaders for different needs and situations.

b) The importance of leadership roles is overestimated because of a core human need for power. Not in all settings is the role of a leader as critical as appears to be.

c)Continued rivalry as a procedure of filling a leader role is much more important than the particular personality who holds this role as it is the natural law of continued adaptation to changing environment.

d)Establishing the right competitive culture in organizational settings should be the first priority. Sales managers should compete by number of sales - not only individual sales, but collective ones - and one of these best sales managers should get a sales director role, not a salesman who knows the company internal politics and budgeting rituals better than others, and not a lucky manager who passed synthetic scoring and was evaluated highly on an interview.

\section{Discussion}

The role-based leadership theory provides a generalized overview on the leadership topic and makes the leadership phenomenon closer to a formal scientific term. Most recent theories focus on influence, persuasiveness, motivation and other behavior factors in order to train or select the best leader. Research and theories on these facets of leadership are not criticized by the role-based leadership theory as they explain how to compete for the role and who should win. Nevertheless, the theory advises scientists and business practitioners to pay more attention to the leader selection and assigning procedure and allow the laissez-faire policy to guide the process of leader selection. Companies will benefit more when the tools a candidate uses in the leader competition correspond with the company values and goals.

The attempts at an artificial selection of leaders, based on criteria which were decisive in a previous situation, only impair the organization's capacity to adapt. All too often, those who make their way to the organization's leadership are not those who are able to improve the company's competitiveness, but randomly selected people whose value has been overestimated in an attempt at artificial selection.

Garcia and Tor [39] found in their study that exceeding a level of competitors decreased motivation to compete, as increased number of players decreased chances of an individual to win. In corporate settings, if all men compete for the role of general manager, it might have negative consequences. To avoid this, corporate culture should promote plural leadership in the organization. Leadership roles might 
Citation: Gotsdanker A (2018) Leadership in Social Organizations from Primates to Humans: The Role of a Leader in Changing Team Direction. Clin Exp Psychol 4: 195. doi: 10.4172/2471-2701.1000195

be separated by functionality of work, such as a technical leader, a sales leader, a production leader, who does not necessarily hold a managerial role. Leadership and managerial roles could be distinguished [40-43].

\section{Conclusion}

From role-leadership theory point of view a "devotion" power of a charismatic leader could be explained as a voluntary reciprocal acceptance of roles. Followers believe in the leader and accept his power, their obedience an intention to get their needs satisfied. The power of the leader depends mostly on criticalness of the situation, and on the intensity of the needs and desires of the followers. Because of inertness of our beliefs [42], the charismatic leader accepted by a team can move the group far away from its initial desires.

The theory is generalized now and has to be discussed and conceptualized further. The presented hypotheses of completive leader selection and of the importance of the role itself have to be studied empirically in organizational settings.

\section{References}

1. McClelland DC (1961) The Achieving Society. Van Nostrand, New York.

2. McClelland DC (1975) Power: The Inner Experience. Halsted Press, Irvington Publishers, New York.

3. McClelland DC, Burnham DH (2008) Power is the Great Motivator. Harvard Business Press, Boston, Mass.

4. Vroom VH, Jago AG (2007) The role of the situation in leadership. Am Psychol 62: $17-24$.

5. Fiedler FE (1967) A Theory of Leadership Effectiveness. McGraw-Hill, New York.

6. Morgan G (1986) Images of Organization. Sage Publications, Beverly Hills.

7. Scott WR (2003) Organizations: Rational, natural and open systems. Upper Saddle River, Prentice Hall, NJ.

8. Blanchard KH, Zigarmi P, Zigarmi D (2011) Leadership \& the One Minute Manager: Increase Effectiveness by Being a Good Leader. Harper Collins Publishers, London.

9. Evans MG (1968) The Effects of Supervisory Behavior upon Worker Perception of Their Path-Goal Relationships.

10. Hersey P, Blanchard KH (1969) Management of organizational behavior: Utilizing human resources. Englewood Cliffs, NJ: Prentice-Hall.

11. Hersey P, Blanchard KH, Johnson DE (2013) Management of Organizational Behavior. 10th edn. Pearson.

12. Bass B (1985) Leadership and Performance beyond Expectations. Collier Macmillan.

13. Bono JE, Judge TA (2004) Personality and transformational and transactional leadership: A meta-analysis. J Appl Psychol 89: 901-910.

14. Casimir G, Waldman DA (2007) A cross cultural comparison of the importance of leadership traits for effective low-level and high-level leaders: Australia and China. International Journal of Cross Cultural Management 7: 47-60.

15. Hough LM, Oswald FL (2008) Personality testing and industrial-organizational psychology: Reflections progress and prospects. Ind Organ Psychol 1: 272-290.

16. Judge TA, Bono JE, Ilies R, Gerhardt MW (2002) Personality and leadership: A qualitative and quantitative review. J Appl Psychol 87: 765-780.

17. Zaccaro SJ (2007) Trait-based perspectives of leadership. Am Psychol 62: 6-16.
18. Hogan R, Kaiser RB (2005) What we know about leadership. Rev Gen Psychol 9: 169-180.

19. Yukl G (1999) An evaluation of conceptual weaknesses in transformational and charismatic leadership theories. Leadership Quarterly 10: 285-305.

20. Neck CP, Houghton JD (2006) Two decades of self-leadership theory and research: Past developments, present trends, and future possibilities. Journal of Managerial Psychology 21: 270-295.

21. Conger JA, Kanungo RN, Menon ST (2000) Charismatic leadership and follower effects. J Organ Behav 21: 747.

22. Weber M, Henderson AM, Parsons T (1947) Max Weber, the theory of social and economic organization. Glencoe, III: Free Press \& The Falcon's Wing Press.

23. Waal FD (1982) Chimpanzee politics. Cape, London.

24. Whiten ABRW (1997) Machiavellian Intelligence II: Extensions and Evaluations. Cambridge University Press, Cambridge; New York, NY, USA.

25. Byrne RW, Whiten A (1988) Machiavellian Intelligence: Social Expertise and the Evolution of Intellect in Monkeys, Apes and Humans. Clarendon Press.

26. Helder R, Desor D, Toniolo AM (1995) Potential stock differences in the social behavior of rats in a situation of restricted access to food. Behav Genet 25 483-487.

27. Barrette C, Vandal D (1986) Social rank, dominance, antler size, and access to food in snow-bound wild woodland caribou. Behaviour 97: 118-146.

28. Bernstein IS (1969) Stability of the status hierarchy in a pigtail monkey group (Macaca nemestrina). Anim Behav 17: 452-458.

29. Darwin C (1859) On the Origin of the Species by Natural Selection: Murray.

30. Saidel E (2017) On psychological explanations and self-concepts (in some animals). In: Beck J, Andrews K (eds) The Routledge Handbook of Philosophy of Animal Minds, Routledge. pp: 1-10.

31. Beck J, Andrews K (2017) Introduction of the Routledge Handbook of Philosophy of Animal Minds. Routledge.

32. Zhuravlev AL, Zankovsky (2017) Tendencies of the development of organizational psychology. Psikhologicheskii Zhurnal 38: 77-88.

33. Maynard, Smith J (1982) Evolution and the Theory of Games. Cambridge University Press, Cambridge; New York.

34. Nash J (1951) Non-cooperative games. Ann Math 54: 286-295.

35. de Waal FB (1986) The integration of dominance and social bonding in primates. Q Rev Biol 61: 459-479.

36. Kirby R (2018) Monkey Thieves. In: Collis C (Producer): National Geographic.

37. Poyarkov A (1986) Historical (biographical) method of the description of social organization and behavior of stray dogs. Research Methods in Ecology and Ethology. pp: 179-199.

38. Maslow AH, Frager R, Fadiman J (1970) Motivation and personality. Harper \& Row New York.

39. Garcia SM, Tor A (2009) The N-effect: More competitors, less competition Psychol Sci 20: 871-877.

40. Kotterman J (2006) Leadership versus management: What's the difference? Journal for Quality \& Participation 29: 13-17.

41. Yukl G (1989) Managerial leadership: A Review of theory and research. Journa of Management 15: 251-289.

42. Heider F (1946) Attitudes and cognitive organization. J Psychol 21: 107-112.

43. Whiten A, Byrne RW (1997) Machiavellian Intelligence II: Extensions and Evaluations. Cambridge University Press, Cambridge; New York, USA. 